\title{
On an induction magnetic compass
}

\section{Mascart}

To cite this article: M. Mascart (1884) On an induction magnetic compass, Philosophical Magazine Series 5, 17:103, 78-79, DOI: 10.1080/14786448408627484

To link to this article: http://dx.doi.org/10.1080/14786448408627484

册 Published online: 29 Apr 2009.

Submit your article to this journal

Џ Article views: 2

Q View related articles $₫$ 
If these magnitudes $x$ and $y$ are determined, the calculation of the force is best made on the supposition that all magnetism is concentrated in the points in question, and comes out then very simple.

If the magnetic moment of a magnet is then accurately determined in absolute value, and can any time be accurately controlled, then by means of magnetometrical methods all other magnetic moments and all current-strengths may be easily reduced to them. Magnetic moments alter indeed; but with steel not quite recently magnetized and well hardened, changes occur such as the earth's magnetism experiences sometimes in five minutes. Hence we get a far more certain absolute determination of current-strengths, when we compare their magnetic strengths with the moment of a well-hardened steel bar, than when we reduce them by means of the tangent galvanometer to the terrestrial magnetism, which, from the concealed masses of iron in our buildings, may show a quite different value at a distance of a few feet from the place of observation.-Sitzungsberichte der Akademie der Wissenschaften zu Berlin, April 1883.

\section{ON AN INDUCTION MAGNETIC COMPASS. BY M. MASCART.}

Weber's inductometer enables us to determine the magnetic inclination by measuring the currents induced in a conducting frame, which is first turned through an angle of $180^{\circ}$ about a horizontal axis starting from the horizontal plane, and then about a vertical axis starting from a plane perpendicular to the magnetic meridian. Such is the method in use in many observatories.

If the apparatus is so arranged that the axis of rotation of the frame is in any direction in the magnetic meridian, and if we seek by trial for two directions such that for an angular rotation of $180^{\circ}$ the needle of the galvanometer experiences equa?. impulses in opposite directions, the line bisecting these two directions will give the position of equilibrium of a dipping-needle. This second method has recently been proposed by $\mathbf{M}$. Wild.

It is c'ear that the incluced currents must be zero, when the axis of rotation of the frame is exactly parallel to the direction of the magnetic force.

With the ordinary method of observation, which consists in turning the frame through $180^{\circ}$, we obtain the same degree of exactitude as by measuring the angles of throw; but the null method enables us to dispense with any measurement of the throw, as well as any regulation of the initial and final positions of the movable frame. We have in this the adrantage that, if we are near the wished-for direction, we may, by alternate movements of the frame of the same period as that of the oscillations of the needle, multiply the angles of throw, and thus demonstrate the existence of a deflection which in itrelf would have been inappreciable. The accuracy of the method is thus considerably increased; we may then greatly 
diminish the dimensions of the rotatory frame, and it is convenient to use a galvanoseope of suitable resistance to which the maximum of sensitiveness is imparted.

I have for some years tried to realize this experiment by means of an apparatus which can be readily carried about. It consists of an azimuthal circle on which mores an arrangement which supports a ring movable about a horizontal axis; the angle which this ring makes with the vertical is measured by a vertical circle; the frame, which is only 0.12 metre in diameter, is supported by the ring and can turn about an axis perpendicular to that of the ring. The dimensions of the instrument do not exceed those of an ordinary dip-needle.

By a series of systematic trials we can first find the angle of the ring at right angles to the magnetic meridian; by a second series the axis of rotation of the frame is brougbt into the direction of the dipping-needle. With the inversions necessary to eliminate the errors of reading, the entire observation does not take half an hour: this is scarcely the time required to determine the inclination by the dipping-needle.

As regards the accuracy of the results, it does not appear to be less than that of the dip-circles, the handling of which is so delicate. I will give as an instance some observations recently obtained by M. Morneaux at the observatory of the Pare Saint-Maur.

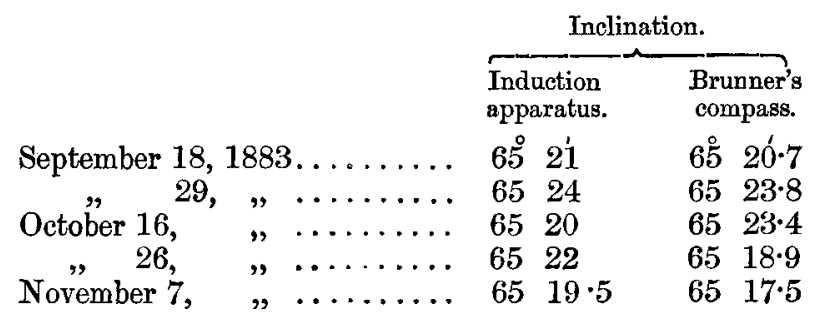

If it be remembered that the observations were not made simultaneously, and that the results given by dip-needles of different patterns, observed at the same time, scarcely agree better, it will be seen that it is difficult to give any good reason for preferring one method to the other.

The reading for the magnetic meridian is sufficiently accurate to allow us to determine the declination to within a minute; hence by adding a telescope we get a true magnetic theodolite.

I may add that the dimensions of the frame may be still further diminished by introducing soft iron. The induced currents are thus made far stronger without any inconvenience, for the changes of magnetization would still be null for any rotation about the direction of the terrestrial force.-Comptes Rendus, Nov. 26. 